\title{
Editorial
}

\section{Política nacional de educação permanente em saúde: desafios e perspectivas}

\author{
Elisabete Ferreira Mângia ${ }^{1}$
}

\begin{abstract}
Em nosso país a Política Nacional de Saúde deve ser vista como um processo contínuo que depende de iniciativas cotidianas dos governos, gestores, trabalhadores e cidadãos para a sua consolidação, aprimoramento e continuidade. Apesar dos avanços contidos na formalização do Pacto pela Saúde (Brasil, 2006) para o fortalecimento do modelo de gestão, assistimos a diversas versões do Sistema Único de Saúde (SUS) operadas pelos municípios que adotam a opção privatizante e repassam a gestão do sistema ou partes dele para Organizações Sociais, nem sempre comprometidas com suas principais diretrizes.

Como resultado se vê, em muitas situações, o grande distanciamento entre o que é oferecido pelos serviços e a perspectiva da atenção integral, humanizada e de qualidade, ou seja com os marcos principais da reforma sanitária brasileira.

Enfrentar os conflitos e contradições presentes hoje no SUS depende do protagonismo dos múltiplos atores que o compõe. Os trabalhadores de saúde, que poderiam desempenhar um papel fundamental nessa luta, muitas vezes não são suficientemente informados, formados e preparados e isso se torna um fator que fragiliza diversos aspectos da assistência, da organização e gestão das redes de serviços.

Não estamos aqui defendendo a formação como medida compensatória ao que falta aos trabalhadores, nem acreditamos que a oferta indiscriminada de cursos possa trazer alguma contribuição significativa para esse cenário e concordamos com Merhy (2005) que propõe que há

"necessidade de olharmos de outros modos explicativos para esta relação de dobra: educação em saúde e trabalho em saúde, na qual é impossivel haver separação dos termos. Um produz o outro. Com efeitos fundamentais tanto para a construção da competência do trabalhador, quanto para a expressão de seu lugar enquanto sujeito ético-politico produtor de cuidado(...) (p.172)".

É nesse contexto que poderíamos compreender a importância da defesa e aprimoramento da "Política Nacional de Educação Permanente em Saúde" (PNEPS) recentemente alterada pela Portaria GM/MS n ${ }^{\circ} 1.996$, de 20 de agosto de 2007. Instituída em 2004 pela Portaria GM/MS no 198, a PNEPS é definida como um dispositivo que busca favorecer mudanças nas práticas do trabalho em saúde, que articula o sistema de saúde com as instituições formadoras na identificação de problemas cotidianos para a formulação de processos educativos que respondam a realidade e necessidades do SUS.

A nova Portaria teve como ponto de partida um trabalho de avaliação da estratégia configurada pelos Pólos de Educação Permanente (que estruturaram a implantação da política) realizada pelo Departamento de Medicina Preventiva da Faculdade de Medicina da
\end{abstract}

1. Docente do curso de Terapia Ocupacional do Departamento de Fisioterapia, Fonoaudiologia e Terapia Ocupacional da Faculdade de Medicina da Universidade de São Paulo, editora da Revista de Terapia Ocupacional da USP. 
Universidade de São Paulo (USP) e propõe uma nova forma de gestão que implica no enraizamento da tarefa da Educação Permanente no contexto dos Colegiados de Gestão Regionais por meio da criação das Comissões Permanentes de Integração Ensino-Serviço (CIES)

"As Comissões Permanentes de Integração Ensino-Serviço (CIES) deverão ser compostas pelos gestores de saúde municipais, estaduais e do Distrito Federal e ainda, conforme as especificidades de cada região, por: I - Gestores estaduais e municipais de educação elou seus representantes; II - Trabalhadores do SUS elou suas entidades representativas; III - Instituições de ensino com cursos na área da saúde, por meio de seus distintos segmentos; e IV-Movimentos sociais ligados à gestão das políticas públicas de saúde e do controle social no SUS." (Brasil, 2007)

Elas deverão assessorar os Colegiados de Gestão Regional na formulação, condução e desenvolvimento dos Planos Regionais de Educação Permanente em Saúde em sua respectiva área de abrangência, de acordo com as diretrizes nacionais, estaduais e municipais para a educação em saúde. Esses planos deverão ser pactuados regionalmente e aprovados pela Comissão Intergestores Bipartite (CIB), de forma a fazer com que as ações de educação sejam parte integrante e indissociável do sistema de saúde.

Além de detalhar os processos para o desenvolvimento das ações de educação permanente a Portaria também define a alocação de recursos que serão destinados anualmente pelo governo federal aos estados e municípios e que serão transferidos para os Fundos Estaduais e Municipais, configurando assim a descentralização administrativa desse processo.

A atual PNEPS reflete amadurecimento e seriedade e exige a ação coordenada e cooperativa dos atores envolvidos de cuja responsabilidade depende o seu sucesso ou fracasso.

È importante que as instituições formadoras e associações de ensino das diversas categorias profissionais do campo da saúde, gestores e profissionais atuantes na luta pela defesa do SUS assumam seu papel que hoje inclui a necessidade de sensibilização de todos para a importância de desenvolvimento de processos formativos articulados com as reais necessidades do sistema e de acordo com suas diretrizes. E mais que isso assumam o desafio colocado por Merhy de

"pensar uma nova pedagogia - que usufrua de todas que têm implicado com a construção de sujeitos auto-determinados e comprometidos sócio-historicamente com a construção da vida e sua defesa, individual e coletiva - que se veja como amarrada a intervenção que coloca no centro do processo pedagógico a implicação etico-política do trabalhador no seu agir em ato, produzindo o cuidado em saúde, no plano individual e coletivo, em si e em equipe". (Merhy, 2005, p.174)

Assim convidamos os nossos leitores a conhecerem o conteúdo dessa iniciativa e tomarem uma posição ativa na construção de processos que possam trazer mudanças profundas para a qualidade da oferta de serviços e qualificação dos trabalhadores de saúde.

\section{REFERÊNCIAS}

MERHY E. E. O desafio que a educação permanente tem em si: a pedagogia da implicação Interface. Comunic, Saúde, Educ, v.9, n.16, p.161-77, set.2004/fev. 2005.

BRASIL. Ministério da Saúde, Portaria GM/MS n 1.996 , de 20 de agosto de 2007, disponível em http:// portal.saude.gov.br/portal/arquivos/pdf/Portaria_1996-de_20_de_agosto-de-2007.pdf

BRASIL. Ministério da Saúde. Secretaria Executiva. Departamento de Apoio à Descentralização.. Diretrizes operacionais dos Pactos pela Vida, em Defesa do SUS e de Gestão, Brasília, 2006, disponível em http://www.saude.gov.br/bvs 